\title{
WHAT MAKES THEM SNAP? GRATIFICATIONS OF USING SNAPCHAT BY GENERATION Z
}

\author{
Aakash Kamble ${ }^{1 *}$, Supriya Desai ${ }^{2}$, and Smita Mehendale ${ }^{3}$ \\ ${ }^{1}$ Indian Institute of Management Jammu, Old University Campus, Canal Road, \\ Jammu-180016, India \\ ${ }^{2}$ Indira Global Business School A/P. Parandwadi, Tal. Maval, Dist. Pune-410506, India \\ ${ }^{3}$ Symbiosis Institute of Management Studies (SIMS), \\ Symbiosis International (Deemed University) (SIU), Pune, India \\ *Corresponding author: kamble.aakash@outlook.com
}

Published online: 4 June 2021

To cite this article: Kamble, A., Desai, S., \& Mehendale, S. (2021). What makes them snap? Gratifications of using Snapchat by Generation Z. Asian Academy of Management Journal, 26(1), 1-23. https://doi.org/10.21315/aamj2021.26.1.1

To link to this article: $h$ ttps://doi.org/10.21315/aamj2021.26.1.1

\begin{abstract}
This paper aims to understand the motivations and behavioural patterns of Snapchat use by Generation Z (Gen-Z) and their social relationships with friends and romantic companions. Focus group discussion and in-depth interview methodology were employed to conduct the research with 49 respondents participating in focused group discussions. The respondents reported Snapchat being adopted for connecting with friends as it provided them with secure and authentic experience over other social media platforms. The gratifications gained from the use of Snapchat by Gen $Z$ users were identified emerging from the features and experience of using the technology platform. The results were supported for uses and gratifications as the respondents justified the ephemerality of Snapchat being useful, the gratifications gained from snapping with friends and social groups. Snapchat was seen as a useful medium for security, privacy and ephemerality it provided along with a medium for authentic communications with friends and romantic companions.
\end{abstract}

Keywords: Generation Z, Snapchat, uses and gratifications, ephemeral social media, social relationships

(C) Asian Academy of Management and Penerbit Universiti Sains Malaysia, 2021. This work is licensed under the terms of the Creative Commons Attribution (CC BY) (http://creativecommons. org/licenses/by/4.0/). 


\section{INTRODUCTION}

Technology and digital media have led to an enormous change in human interactions with their counterparts and influenced their relationships over social networks. Technologies like texting, then social media, and now ephemeral social media has led this shift. The use of technology by Generation Z (Gen-Z) has seen an unprecedented increase (Desai \& Lele, 2017) and has made it a regular part of their lives (Coyne et al., 2013; Vaterlaus et al., 2015). Gen- $Z$ comprises of young adults born after 1995 and proactive towards adopting technological changes and similar to the earlier Gen-Y. The key difference between the two generations stems out from the fact that, Gen-Y witnessed the rise of internet and digital technologies, adapting to the changes; whereas, Gen- $Z$ being accustomed with the use of internet and technology.

With access to multiple media simultaneously, Gen-Z has been at the forefront of technology adoption and can access both entertainment and social networks simultaneously (Vaterlaus et al., 2016). While in Gen-Z, the eldest user is into his mid-20s, the cohort of Gen-Y has reached the age of 40 years. Conventional social media platforms enable the audiences to communicate their message which can then be experienced and re-experienced by the communicator and even broadcasted to new audiences (Bayer et al., 2016). Unlike the mainstream social media Facebook and Twitter - Gen- $Z$ is part of a wave of ephemeral social media like Snapchat which take the privacy of the messages to the next level. Ephemerality relates to the deletion of the message in a short time. Another peculiar feature of ephemeral social media is with the one-to-one communication among the young adults having close relationships. Snapchat differs due to the temporary nature of images and videos which can be seen by the receiver from 1 second to a 24 hours maximum (Billings et al., 2017).

The amount of time spent by Gen- $Z$ with technology is more than any other age group cohort, and due to this, it is important to know the influences of technology on the Gen-Z users and their relationships (Yang et al., 2014). The motivations behind the use of Snapchat by Gen-Z users and their behavioural patterns are examined in the study. The study employs a two-pronged strategy to examine firstly, the gratifications for the motivations for using Snapchat and the benefits derived by the Snapchat use. Secondly, the study examines the structure and the nature of relationships maintained by Gen-Z users on Snapchat. Thirdly, the research examines the differences between ephemeral social media and mainstream social media platforms to study the motives and adoption of Snapchat by Gen-Z. Finally, the research investigates the social conflicts arising among Gen- $Z$ and its consequences in their relationships on Snapchat. The study employs the exploratory 
method to identify the perceived influence on the social relationships on Snapchat behaviours. The study employs focus groups discussions for respondents aged 18 to 24 years $(n=49)$ to study their perceptions of the ephemerality of Snapchat and how it aides their communications in relationships. The perception of Gen-Z can lead to behavioural outcomes thus mandating the study. The researchers set to answer the following question: Why do Gen-Z adopt Snapchat and how its ephemerality helps them maintain relationships?

\section{THEORETICAL FRAMEWORK}

\section{Ephemeral Social Media}

Communication medium which are private and do lead to a data breach are present since long. Yet a threat looms over the users concerning data theft and cloning of the data. Due to this challenge, newer media wherein the communications are erased after a short time has grown in importance. This ability of social media platforms to store the messages for a short time and deleting them from the network completely makes them ephemeral. Application platforms like Snapchat, Facebook, and Instagram are the most popular ones present in the social mediascape. Ephemerality when paired with anonymity presents the users with increased privacy (Bayer et al., 2016). Earlier relevant researches have focused on the examination of anonymous sites like YouBeMom and 4chan, both of which being temporary online sharing sites (Morris, 2014; Schoenebeck, 2013) and also related with Facebook newsfeed streaming's ephemerality nature (Kaun \& Stiernstedt, 2014). All of the studies have provided a perspective on the ephemerality of the messages and their association compared to the ones with permanent platforms.

Face-to-face interaction amongst individuals by its nature has always been ephemeral communication in principle (Hollan \& Stornetta, 1992). Even in audio and/or video calling, the channels mediating the services do not store the record of it by default. Thus, the properties of ephemeral social media are similar to the properties of face-to-face communication due to synchronous communication. Despite this difference, social media has made ephemerality as an important ingredient for the enhanced user experience.

Image sharing application with an ability to discard the images has been presented in earlier studies (Counts \& Fellheimer, 2004). The users of that application favoured the sneak peek into their friends and families lives with the ephemerality of the photos. The participants of the study proposed the deletion of untagged photos. Confide is another example of an ephemerality-based application which 
enables users to view the text messages upon scrolling over them. Similarly, users can view the image only when they press and hold the image. Upon such activation, the interface prompts the user with an alert message on content deletion after a stipulated time.

Ephemerality today has become a norm with several social media platforms as it is treated as a feature and not merely a glitch (Bannon, 2006; Mayer-Schönberger, 2011). In fact, the data preservation without the control of users over it can lead to serious personal consequences, based on the evolution of personal and social needs (Mayer-Schönberger, 2011). Snapchat offers the users with ephemerality and privacy due to the disappearing nature of the content generated by the users. Snapchat goes against the popular belief of cultural memory by integrating the need to forget the message (Soffer, 2016). Soffer (2016) argues that orality has become inseparable from an application's features and design - the same being the case with Snapchat.

A report by Statista (2018) cites Snapchat being more popular amongst the younger generation's individuals belonging to Gen-Z. The unique characteristics of temporality and ephemerality of Snapchat mediate the intimacies due to its technological affordances (Handyside \& Ringrose, 2017). Snapchat in its entirety is more of a private communication medium providing the public with a chanto escape from a Facebook social media platform which is open and can be viewed by many (Utz et al., 2015). Besides providing ease of use and an uncluttered interface design, Snapchat offers unique features related to the disappearance of content after a specific period. The self-destructive nature of messages leads to removal of reservation among users with regards to the sharing of online content (Piwek \& Joinson, 2016). According to Velez (2014), the ephemeral bursts of effect in Snapchat due to entertainment, curiosity, and even boredom exchanges occurring during interactions. Snapchat blurs the boundary between documentation and lived experience due to the ephemeral nature of the content (Jurgenson, 2011). Researchers have also examined the use of self-expression of millennials on Snapchat and its impact on their purchase intentions. The research showed that Snapchat use gratifies and influences the expectations of millennials thus increasing the relationship with product/service brands (Flecha-Ortíz et al., 2021). In the case of Snapchat, the ephemerality of the platform ensures snaps to disappear in a predefined time, leaving no evidence of such social communications. Research related to the perceived privacy and security among the Snapchat users suggested the security concerns and the use of sensitive content (Roesner et al., 2014). 


\section{Generational Cohorts, Technology, and Social Media}

Although the use of technology is seen to be prevalent in society, differences are occurring in the use and consumption of technology based on age (Van Volkom et al., 2014). Previous studies have suggested that the earlier generations like Gen-X have access to internet and smartphones and are just as likely to use and consume mobile internet services as to the recent generations (Madden et al., 2013). When compared with the younger generations, the older adults have less interest in technology along with less acquaintance with the different technologies thus affecting the use of technology among users from older generations (Czaja et al., 2006). The younger generations seem to know their way around different technologies (Olson et al., 2011) and have positive attitudes towards technology use compared to earlier generations (Purcell et al., 2012; van derKaay \& Young, 2012).

Given the generational differences existing between people, the boundaries of the generational divide are unclear - and the studies concerning the change in behaviour of people need to be investigated. Tapscott (2009) in his book, Grown up Digital: How the Net Generation is Changing Your World, provided a characterisation of different generations. Based on it, the most recent generation considered are called Echo Boomer and also known as the net generation or Gen-Y (Leung, 2013) and born between 1981 to 2000 . The net generation or Gen-Y is accustomed to the use of computers compared to their elder counterparts and more likely to be online consumers and also use social media (Leung, 2013). The boundaries of where an earlier generation ends and the new Gen-Z starts are unclear though, based on earlier studies the users born from 1997 can be termed as Gen-Z (Dimock, 2019). Other studies take a broader perspective by noting the users born between 1995 and 2000 can be termed as Gen-Z (Seemiller \& Grace, 2016). With no formal process for naming the youngest people as Gen-Z, this name is included in popular dictionaries like Merriam-Webster and carries a momentum even in online searches (Dimock, 2019).

According to PEW research, Gen-Y or millennials were aged between 5 to 20 years when the 9/11 terrorist attacks in the United States of America occurred and they carry distinct memories of it as opposed to the people born after 1995 that have little or no memory of this event (Dimock, 2019). The authors in the present research consider this distinction to form a boundary with the starting age of Gen-Z users. According to Aksoy et al. (2013), social media has existed for Gen-Y and they have grown along with the same considering their starting year of 1981. This generation has adopted different technologies and has witnessed the advent of the internet and social media, and has consumed the different digital 
media available to them. The subsequent Gen-Z has ubiquitously used technology and social media learning from their parents and elder siblings. The present study considers the Gen-Z starting from 1996 based on the classification made in earlier studies (Dimock, 2019; Seemiller \& Grace, 2016).

While considering Gen-Z, they are said to be a socially empowered and technologically literate generation (Desai \& Lele, 2017) though the earlier Gen-Y has also been brought up during the technological innovations and has used social media. Considering the eldest member of Gen-Y born in 1980 would be 40 years old today, the person may have adapted social media and internet as they came to age, as opposed to the Gen- $Z$ assumed faster internet connectivity, social media use, WiFi broadband, and on-demand entertainment (Dimock, 2019). The ingress of digital media into the lives of Gen- $Z$ is been seamless according to the research (Dimock, 2019). Gen- $Z$ are tech-savvy individuals present on social media platforms and communicate over such social media platforms rather than having direct contact with people. The earlier millennial generation pioneered the use of Facebook with its infamous campaign of the beer-bong selfie. Gen-Z has embraced Facebook medium but they prefer being on ephemeral platforms liked Secret or Whisper and even Snapchat (Williams, 2015). Gen-Z is known to handle short, real-time information with the use of pictures. Due to the short span of communication and attention period, messages are supposed to be created with a context of less is more (Töröcsik et al., 2014). Gen-Z uses social media to gather and spread information and also share their experiences using videos, pictures, and links (Relander, 2014). Over the years, generational cohorts have existed with the technology and have adapted to the changing technologies, thus resulting in the incremental use of digital mediums. Gen- $Z$ considered for the research is the generation who have taken technology, internet, and digital platforms to be granted as they were born when the proliferation of technology was ubiquitous. This distinction among the earlier Gen-Y and the present Gen-Z posits investigation into their use of social media platform Snapchat.

\section{Snapchat and Gen-Z}

Teenagers while growing up seek increased independence and yet rely on their parents for a variety of resources (Aquilino, 2006). With growing concern over the rampant use of social media by the Gen-Z, investigations into it are warranted for (Coyne et al., 2013). The emergence of social media impacts the relationship between the parent and their young adult (Barrie et al., 2019; Ramsey et al., 2015; Vaterlaus et al., 2016). Relational conflicts with parents and relatives due to communication over social media platforms (Gentzler et al., 2011) are prevalent though the result of it were not confirmed during a continuation study (Ramsey et al., 2013). 
Recent studies related to the use of cell phones among young adults focus on texting with their parents and relatives (Crosswhite et al., 2014; Mei et al., 2018). Among various reasons for texting family and friends are planning activities, sharing information, sending pictures and jokes, and having a general conversation. Being a mobile app, Snapchat does not meet their social need. Keeping in touch and connect with the family and friends proves to be the highest motivation for its users while considering the use of Snapchat (Utz et al., 2015). Snapchat being a playful mobile instant messaging service finds its use in rapid communication and content sharing with small groups of close friends, partners, and family (Piwek \& Joinson, 2016). Though few studies have pointed out that Snapchat being an ephemeral social media platform does not hold importance among young adults for texting to their relationships and connections (Vaterlaus et al., 2016). Based on this, this study investigated the gratifications for Gen-Z based on their use of Snapchat and its emergence.

\section{Uses and Gratifications of Social Media by Gen-Z}

The uses and gratifications theory developed by Katz et al. (1973) identified eight types of uses and gratifications. The active audience consuming the media does not simply consume media but they do so with an end with an end-goal in minds (Katz et al., 1973). The theory holds relevance in social media research due to its origin from communications literature (Whiting \& Williams, 2013). Quan-Haase and Young (2014) consider the uses and gratifications theory on its historical building and further consider it for the use of social media. The theory postulates that individuals will consume media to fulfil their needs thus leading to gratifications (Weaver Lariscy et al., 2011) with the gratifications predicting the initial and recurring media use (Kaye \& Johnson, 2002). The core of the uses and gratifications theory explores "how, why, and what purpose people use media in their everyday lives" (Quan-Haase \& Young, 2014, p. 269). For satisfying the individuals' technology needs, the individuals associate their need gratification with definite technology choices thus creating competition (Vaterlaus et al., 2016). The gratifications generated by social networking sites were studied in earlier research (Sundar \& Limperos, 2013). In the research by Sundar and Limperos (2013), the authors investigate the changes in gratifications considering the emergence of social media as opposed to the old traditional media. As mentioned in the research, the gratifications derived from a given media could be triggered due to the features experienced by users of that media as opposed to being drive by the innate needs of the users.

Social media is consumed by the young adults every day and is being touted as an integral part of their lives with every picture and post reflecting the users' life, 
experience, and opinions (Dvořák, 2018). A direct relationship is seen between the use of social media and social involvement than entertainment purpose (Nyland et al., 2007). Though abundant research is available on social media and the uses and gratifications theory, research on ephemeral social media platforms like Snapchat is scarce (Punyanunt-Carter et al., 2017). The young users belonging to Gen-Z cohort understand the use of Snapchat and can identify and relate themselves with the platform while not having to deal with parents, family members, and undesirable users on Snapchat opinions (Dvořák, 2018). According to Punyanunt-Carter et al. (2017, p. 871), earlier studies on the uses and gratifications theory and social media were carried out in four categories, namely: (1) passing time, escape, and relaxation; (2) enjoyment and excitement; (3) information; and (4) companionship and social interaction.

To summarise, the literature provides insights into Snapchat as an ephemeral social media platform used by Gen- $Z$ and also their behavioural traits while utilising it. Gen-Z uses Snapchat to maintain social connections with their romantic partners, friends, and family. This media is preferred over mainstream social media platforms due to its privacy, security, and ephemerality. Further research is mandated to study the motives and behavioural patterns of Gen-Z.

\section{MATERIALS AND METHODS}

The research employed focus group discussions to ascertain and record the views shared by the participants on the uses and gratification from Snapchat using the qualitative research method. Melander (2010) reported the effectiveness of focus group methodology to understand the young adult's lived experiences with technology. Further to validate and increase the impact of results, individual indepth semi-structured interviews were conducted. The sample was drawn from the educational institutes in Pune, India with a total of 49 respondents agreeing to participate comprising of 28 female and 21 male respondents aged between 18 to 24 years representing the Gen-Z. The recruiting of the respondents for the focus group discussions were carried out using calling for applications to be a part of the study. Based on the applications received, initial screening was carried out by scrutinising of the applications based on their age and further a written consent was taken from the respondents about participation in the study. A total of seven focus group interviews having seven respondents in each one of them were conducted to reach at a saturation level with the participants in terms of the data.

Participants completed the focus group interviews which lasted for 30 minutes at the maximum. The interviews were video recorded and an independent audio 
recording was also kept in place. A short questionnaire capturing the demographic details of the respondents was captured before the focus groups. The questions for the research revolved around Gen-Z experiences with social media with specifics related to Snapchat use on a routine basis. The study concerned with the motives of Gen- $Z$ to adopt and use Snapchat as a social media platform and to this regards the questions asked during focus group discussions were related to the utility and use of Snapchat and the influence of Snapchat in their social groups. The validity of the results of focus group discussions was measured by conducting individual interviews of eight respondents (four male and four female). Unique information, insights, and trends emerging were subjected to additional interviews. The individual interviews reinforced the trustworthiness of the discussions.

To answer the research question, the researcher collated the data from focus groups and interviews. Thematic analysis using conventional methods was used for the research. The information related to Snapchat was acquired from the focus group discussions conducted during the research. The two independent researchers worked in isolation to highlight the recurring words and themes from the focus groups and interviews represented by the participants.

Further discussions on the commonalities between the two versions of the analysis created 14 coding categories. The 14 coding categories then upon discussion led to five major themes across the research which were then tested for validity. To circumvent the limitations related to bias and stereotyping, Gen- $Z$ respondents from the same area but not part of the cohort were asked to identify the consistency of the results and experiences. Gen-Z reported the results to be a representation of their experiences of Snapchat.

\section{RESULTS}

Based on the codification of 14 categories arising out of the focus group discussion and subsequent interviews, a total of five themes arose from them. These five themes at occasions overlap one another but are important to be included in the results.

\section{Theme 1: Curiosity, Relaxation, and Entertainment}

Snapchat is seen as a medium to deal with boredom and a mode for entertainment by the respondents. The respondents reported they were been driven towards Snapchat due to curiosity about the apps and then relax while scrolling through the moments shared by their friends. Like other social media platforms, Snapchat also 
provides an opportunity for users to see what other people are doing in their daily lives and try to be a part of it through interactions.

Respondent 2: First, I was curious about it and why my friends were hooked to it. Later on, I started using it multiple times daily.

Respondent 13: Well it made more sense to be a part of Snapchat. All my friends made me curious and hence I joined. Now, it's fun to use it.

Respondent 7: It is a stressbuster for me. I scroll through the moments shared by the friends and chat with them.

Snapchat provides the users to interact with their friends and share key moments of their lives. Many of the respondents became part of it to gain acceptance among their peers. Once being a part of the community, the users tend to interact on it on a continuous mode and share moments with friends. Snapchat provides a sneak peek into the lives of their friends. This small close circle of friends is used to each other and do not mind the behaviour.

Respondent 33: Our old group is still intact and thanks to Snapchat. We all discuss the college days and share light moments.

Respondent 16: As I interact only with my close friends, we share a similar understanding of jokes we make. No one gets hurt. I like humor and my jokes are not meant to disrespect my friends. They are aware of it.

Respondent 8: Funny moments like pranks and discussing incidents in college or cafe's is easier here. We all are on the same page as we were part of it.

Curiosity soon leads to entertainment and relaxation which are an integral part of Snapchat users. This has appeared to a larger extent compared to other themes during the focus group discussions. These gratifications form the main purpose of Snapchat and hence the increase in its adoption. 


\section{Theme 2: Privacy and Security}

One of the main themes emerging from the focus group discussions dwelled on the perceived security associated with the use of Snapchat. Gen-Z utilised and consumed Snapchat in different ways for varied means. As mentioned by Respondent 9 due to the disappearing nature of the messages shared with their social connections, the users are least worried about the repercussions arising from their actions.

\begin{tabular}{|c|c|}
\hline & $\begin{array}{l}\text { You can share intimate images with your } \\
\text { partners and need not worry about it being } \\
\text { seen by others. }\end{array}$ \\
\hline Respondent 40: & $\begin{array}{l}\text { Uploading awkward images on Snapchat is } \\
\text { less worrying as it will disappear in no time } \\
\text { and people will forget about it. }\end{array}$ \\
\hline Respondent 9: & $\begin{array}{l}\text { I am least worried about my conversations with } \\
\text { friends and romantic connections. The sense } \\
\text { of security provided (on Snapchat) assures } \\
\text { me the messages and images will never fall in } \\
\text { wrong hands neither it can be used in future. }\end{array}$ \\
\hline Respondent 22: & $\begin{array}{l}\text { Messages being falling into wrong hands is the } \\
\text { last thing on my mind. One less thing to worry, } \\
\text { right? }\end{array}$ \\
\hline
\end{tabular}

The results provide support based on earlier studies (Vaterlaus et al., 2016) mentioning respondents seeking a secure platform for intimate and private conversations with peers. Ephemerality plays an important role in providing a safe and secure platform to fulfil the needs of Gen-Z.

Respondent 11: I feel secure to interact (on Snapchat) as I am least bothered of my interactions being heard and snooped upon.

Respondent 18: I can control who can view my message and for how long. This is a big plus over other social media platform.

Respondent 30: I control the way it works. No one can randomly check my messages or my status for that matter. 
Due to the ephemerality of the media, the responses and interactions are perceived as natural, thus imitating and showcasing real-life communication patterns. Snapchat provides Gen- $Z$ with self-censorship on content sharing thus removing the obstacles which otherwise are not present on social media in general.

The Gen- $Z$ respondents felt more secure to interact over Snapchat as the risk involved in messages, photos, and interactions getting public is negligible. The respondents referred to other social media platforms being more judgmental due to the public posting on their wall or timeline compared to the ephemerality associated with Snapchat.

\section{Theme 3: Authenticity}

Snapchat's ephemerality results in more authentic information and conversations as opposed to Facebook and Instagram, the respondents felt Facebook and Instagram force users to show a "happy face" or inauthentic front as they worry about being judged or misjudged by peers.

Respondent 25: I post good pictures and share joyful moments
on Facebook to gain acceptance among my
friends and other acquaintances. I always
show the bright side of my life and refrain
from posting the bad or worse.

Snapchat reveals the real face of its users, by showing their opinions and real feelings towards the peers. The peers here can be friends, family, or romantic partners. Being authentic requires self-awareness and self-confidence and due to the disappearing nature of interactions on Snapchat, the users practice it. Even the responses and answers are genuine and true compared to other comments and responses on social media.

As opposed to this, the respondents practice self-censorship on social media platforms like Facebook and Instagram. The messages posted on these platforms cannot be judged as being authentic or not but the photos shared by the users and the 
filtering and editing done to these images can be a measure of authenticity. Higher the level of editing and stylisation of photos posted on Facebook or Instagram lesser will be the perceived authenticity. The same is reported by the respondents.

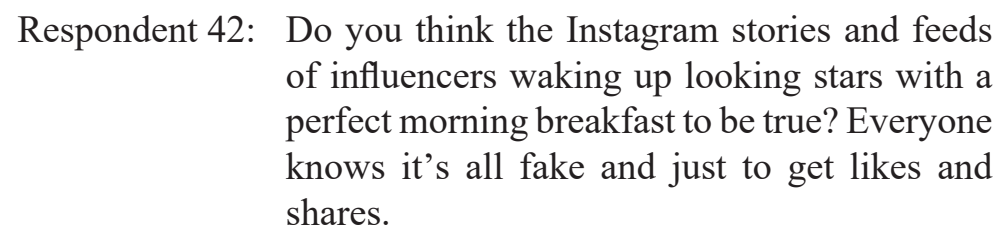

Based on the response mentioned above (Respondent 42), users believe the posts on Facebook (or Instagram) are less authentic and are put up for the sole purpose of gaining wider acceptance. Snapchat provides authenticity and the behaviours of Gen- $Z$ are more spontaneous and authentic.
Respondent 37: You know what, Snapchat is more authentic and truer by sharing the present moment. Facebook, Instagram has become a scrapbook portraying the likes, dislikes, birthdays, travel plans, check-ins and important events in life.
Respondent 38: Facebook is where my friends, family and acquaintances are present. I cannot show the real me there. They will judge me. Snapchat, on the other hand, lets me be me. I worry less. It's a small circle and the real me is seen only by my close friends.

Gen- $Z$ respondents are trying to portray a positive image of themselves on social media platforms like Facebook and Instagram. This portrayal leads widening of their social network and gaining acceptance among them. Hence, a lot of thought and stylisation and editing goes into every post on such platforms. In contrast, the ephemerality of Snapchat means users can post their messages and photos spontaneously thus leading to authentic unfiltered communication.

\section{Theme 4: Conformity and Close Connection with Friends}

Unlike Facebook and Instagram which have both direct and indirect modes for communication, Snapchat relies mostly on direct one-to-one communication. 
Snapchat performs the functions of an instant messaging application as opposed to other social networking sites.

Respondent 14: It helps me communicate freely with my friends and we use the same old slangs from our college days.

Respondent 21: $\quad$ My messages are loud and clear to the ones who can easily put some context to our chats. This helps a lot. You know, unlike Facebook I need to entertain the replies and comments of people who are not aware of the discussion.

Snapchat helps in communicating directly with the recipients having predispositions about the discussions. Snapchat provides a platform comprising of considerably a smaller number of friends which can be as low as a dozen of friends compared to the hundreds on Facebook.

\section{Respondent 23: Even being hundreds of kilometres away, my friends have the same sense of humor as me. The gap is not present and I am aware of what to share with them.}

Snapchat is intended for closed personal communication within friends and loved ones. The communicants share a strong bond and connection leading to deeper ties between them. The loved ones are the romantic partners and couples who use Snapchat to conduct their intimate talks and selfie sharing being assured of the privacy. Snapchat served as an app for strengthening the existing ties as opposed to creating new friends thus maintaining a close-knit circle of friends, family, and partners.
Respondent 30: I was introduced (to Snapchat) by a friend to take our messages to a more private space.
Respondent 15: You cannot trust any messaging apps today. Snapchat provides a sense of security for my private messages. My relationship is thriving due to Snapchat.

This trend of being introduced to Snapchat by a friend or a romantic partner is seen across the majority of respondents. This can be narrowed down to following the fashion with the apps which is common across the generation. Gen- $Z$ is the 
digital natives with a heightened sense for being in sync among their peers by using popular apps and thus being part of the group.

$\begin{array}{ll}\text { Respondent 6: } & \text { Since my school and college days, I } \\ \text { am in contact with the same people and } \\ \text { communicate with them. My group and } \\ \text { friends have increased in number but my old } \\ \text { friends are still a part of my life. }\end{array}$

Gen-Z though independent in their views and behaviour need to be attached to a reference group. This reference groups share similar ways of life and thoughts and are closely knit together sharing a common perspective. The respondents in the research made new friends with whom they are connected over Snapchat but still maintain their connections with friends from school and undergraduate college days.

\section{Theme 5: Exploring Intimacy and Romantic Relationships}

Intimacy finds an important place in the responses of Gen-Z. Snapchat by the virtue of its ephemerality and the privacy and security it provides becomes an ideal app for users to establish romantic relationships with their partners.

Gen-Z revealed that Snapchat aides communicating with their nearest and intimate relationships with their partners, friends, and even family members. The Gen-Z respondents also noted that Snapchat will aid in enhancing their relationship with close relatives and friends and even their loved ones. The participants also emphasised that Snapchat was not only seen by them as a medium to start a new friendship by communicating with their new acquaintances, it also helps in communicating with their existing contacts.
Respondent 10: Snapping new connections at random is weird. Snapchat is personal to me and I use it to chat with my boyfriend. It's safe and private.

Respondent 43: Snapchat provides a more private and intimate platform to chat with my boyfriend.

Snapchat provides a secure and private place for Gen-Z to express their feelings and get intimate with their partners. The romantic partners find the disappearing nature of snaps a boon for communicating with each other. The disappearing 
nature of snaps also means the intimate images and nudity eventually gets deleted. This ensures the users and the females in particular that, the intimacy shared with their partner will not be misused in future.

\author{
Respondent 39: Well, it's all about personal interactions and \\ intimacy with my partner. \\ Respondent 17: It's personalised and the disappearing snaps \\ ensure our connection is hidden from the \\ world around me.
}

Another aspect is based on exploring intimacy and widening the boundaries of messages and photos. Flirting and sexting are common among friends, and few users take their separate ways when the sexting leads to a deeper intimate relationship. The disappearing nature of snaps means the users can explore the boundaries of intimacy. Casual relationships do exist on Snapchat among Gen-Z with friends sharing intimate casual relation and indulging in sexting and photo sharing depicting nudity at occasions.

Earlier research has also included sexting and intimacy and has reported them being prevalent among Snapchat users (Coyne et al., 2013; Utz et al., 2015). The respondents were not very vocal with sharing their information about their intimate chats and relations over Snapchat. The responses though fewer mandates additional research to explore the uses and gratifications for intimate chats on Snapchat.

Snapchat is less risky compared to other social media platforms due to the ephemerality of communication. The disappearing nature of messages ensures the chats are not stored and cannot be accessed after a stipulated time has elapsed. The messages and photos shared during conversations can be awkward and uncomfortable in nature and the sender and/or receiver would want them to be deleted forever with no backup storage. Snapchat offers this facility and hence is seen to adopted by the Gen- $Z$ users widely.

\title{
DISCUSSION
}

Consumers are drawn by a general motivation to use social networking platforms for communicating with people (Dvořák, 2018). These general motivations of users are based on the uses and gratifications theory, wherein the urge to communicate with people forms the need and fulfilment of this need by a relevant medium gratification. The first motive to be a part of a new social media platform is to adopt it out of curiosity. Gen- $Z$ users want to be a part of Snapchat as their friends and 
social groups are a part of it. There is an urge by the users to be seen on this latest trend and gain acceptance among their social group. Relaxation and entertainment are the gratifications gained by their curiosity to adopt Snapchat as a social media platform.

Gen- $Z$ during their quest for a social media platform has several alternatives to choose from. The users are already a part of various mainstream platforms like Facebook and Instagram. The active users of Facebook have reported excessive data collection and an overwhelming amount of unwanted information. The excessive use of user data also raised privacy and security issues for Gen-Z. Due to these concerns, the users want to get rid of the data persistent to social media usage and also consume social media regularly. Due to this dilemma, the users modify their persona on social media platform thus losing the authenticity of the interactions.

The gratifications are provided by the need for authenticity, conformity, and private and secure connections. This leads to distinguishing between the social media platforms based on data-persistency and the ephemerality of the content. Both Snapchat and Facebook have certain inherent flaws and the Gen- $Z$ users have a presence over both of them. But the benefits sought by them are different from both social media platforms. Snapchat provides the users with low visibility but benefits them by providing added security, privacy, and authenticity. Hence the assumptions of uses and gratifications theory are supported as the Gen-Z users reports of using both Facebook and Snapchat but for different purposes. Gen-Z has adopted the ephemeral social media but has not substituted it with the common social media platforms. It is evident from the results that gratifications from the use of Snapchat as a communication medium emerged from the features and experience of the Gen- $Z$ user against the innate needs of the users, thus supporting the earlier studies (Sundar \& Limperos, 2013).

The focus group discussions revealed Gen-Z users' motivation for adopting Snapchat was to communicate privately to reach something desirable. These findings are following the original uses and gratifications (Katz et al., 1973) framework and also concurs with earlier studies. Earlier research focused on texting is a preferred mode of communication among the young generations (Lenhart et al., 2010). This research is consistent with Vaterlaus et al.'s (2016), the Gen-Z respondents reported an inherent flaw in texting which leads to miscommunication and misrepresentation by the counterparts due to lack of emotions. Snapchat here alleviates this potential drawback of texting as the snaps are more emotive and can convey the message in a meaningful manner. Authenticity can be said to be one 
of the main gratifications for the users as Snapchat provides the users to connect quickly using pictures and images and not just text (Vaterlaus et al., 2016).

The study also highlighted the Gen- $Z$ use of Snapchat given it added privacy (Piwek \& Joinson, 2016) and security (Marwick et al., 2017) also confirm the earlier studies. In the research, there was a consensus among Gen-Z participants on Snapchat aiding in enhancing their relationship with friends and social groups along with romantic companions. Snapchat was seen as a personal form of communication against Facebook which is an open public platform. In line with the research by Utz et al. (2015) even Gen-Z individuals in this research reported Snapchat is for personal and private conversation, compared to a large social network. Earlier research has also reported digitally mediated texting lacked several visual and auditory cues and has shown to imply human wellbeing (Holtzman et al., 2017). Snapchat being a social media platform using pictures to communicate emotions has shown to have better and enhance relationships.

The results also confirm the entertainment and relaxation aspect provided by Snapchat during boredom in the form of small and context-rich moments (Barry et al., 2017). With limited responses on sexting provided by Gen-Z during the discussions, the research did not add to the already available knowledge in earlier literature (Coyne et al., 2013; Utz et al., 2015). Confirming the earlier research, Snapchat was extensively used to interact and communicate with romantic partners and also for casual relationships by Gen-Z (Bayer et al., 2016; Kofoed \& Larsen, 2016; Piwek \& Joinson, 2016). The results show maintaining social and romantic relationships on Snapchat is better compared to other platforms like Facebook as Snapchat provides authentic communication due to its ephemerality and also lead to meaningful and private conversations. The results confirm earlier work by Dvořák (2018).

\section{CONCLUSION}

Based on the theoretical background having underpinnings of the uses and gratifications theory approach, the research provides insights into Gen-Z users who make active decisions based on sound judgement and valid reasoning. Based on the assumptions of uses and gratifications, the study explored the gratification provided by Snapchat to the Gen-Z users. This led to the theoretical framework for analysing the target audience and their use of Snapchat. The research identified the influence of ephemeral social media on Gen-Z adoption of Snapchat and the motives behind such adoption. Considering the earlier studies, the research highlighted the gratifications for Gen-Z on adapting Snapchat as a visual medium 
for connecting and communicating with their peers by sharing their identities and photographs (Joinson, 2008; Sundar \& Limperos, 2013). The new gratifications emerging from the research related with the ephemerality of the message and sharing it with personal connections reflect the pre-existent needs already present in the form of their primary needs (Sundar \& Limperos, 2013). The research provided important characteristics and factors which rose from the research like, authenticity, relaxation, entertainment, conformity, and intimacy. Based on the discussions about the privacy issues with mainstream social media platforms and also the use of Snapchat, Gen-Z reported being aware of the benefits and the challenges in using Snapchat and its influence on social and romantic relationships. As the smaller sample size was determined to be sufficient for exploring ephemeral social media and its prevalence use and importance in relationships among Gen-Z, a larger sample base with the longitudinal study is mandated.

\section{REFERENCES}

Aksoy, L., Van Riel, A., Kandampully, J., Bolton, R. N., Parasuraman, A., Hoefnagels, A., Migchels, N., Kabadayi, S., Gruber, T., Loureiro, Y. K., \& Solnet, D. (2013). Understanding Generation Y and their use of social media: A review and research agenda. Journal of Service Management, 24(3), 245-267.

Aquilino, W. S. (2006). Family relationships and support systems in emerging adulthood. In J. J. Arnett \& J. L. Tanner (Eds.), Emerging adults in America: Coming of age in the 21st century (pp. 193-217). American Psychological Association. https:// doi.org/10.1037/11381-008

Bannon, L. J. (2006). Forgetting as a feature, not a bug: The duality of memory and implications for ubiquitous computing. CoDesign, 2(01), 3-15. https://doi. org/10.1080/15710880600608230

Barrie, C. K., Bartkowski, J. P., \& Haverda, T. (2019). The digital divide among parents and their emerging adult children: Intergenerational accounts of technologically assisted family communication. Social Sciences, 8(3), 83. https://doi.org/10.3390/ socsci 8030083

Barry, C. T., Doucette, H., Loflin, D. C., Rivera-Hudson, N., \& Herrington, L. L. (2017). "Let me take a selfie": Associations between self-photography, narcissism, and self-esteem. Psychology of Popular Media Culture, 6(1), 48-60. https://doi. org/10.1037/ppm0000089

Bayer, J. B., Ellison, N. B., Schoenebeck, S. Y., \& Falk, E. B. (2016). Sharing the small moments: Ephemeral social interaction on Snapchat. Information, Communication \& Society, 19(7), 956-977. https://doi.org/10.1080/1369118X.2015.1084349

Billings, A. C., Qiao, F., Conlin, L., \& Nie, T. (2017). Permanently desiring the temporary? Snapchat, social media, and the shifting motivations of sports fans. Communication \& Sport, 5(1), 10-26. https://doi.org/10.1177/2167479515588760 
Counts, S., \& Fellheimer, E. (2004). Supporting social presence through lightweight photo sharing on and off the desktop. In Proceedings of the SIGCHI conference on Human factors in computing systems (pp. 599-606). ACM Digital Library. https://doi.org/10.1145/985692.985768

Coyne, S. M., Padilla-Walker, L. M., \& Howard, E. (2013). Emerging in a digital world: A decade review of media use, effects, and gratifications in emerging adulthood. Emerging Adulthood, 1(2), 125-137. https://doi.org/10.1177/2167696813479782

Crosswhite, J. M., Rice, D., \& Asay, S. M. (2014). Texting among United States young adults: An exploratory study on texting and its use within families. The Social Science Journal, 51(1), 70-78. https://doi.org/10.1016/j.soscij.2013.10.002

Czaja, S. J., Charness, N., Fisk, A. D., Hertzog, C., Nair, S. N., Rogers, W. A., \& Sharit, J. (2006). Factors predicting the use of technology: Findings from the center for research and education on aging and technology enhancement (CREATE). Psychology and Aging, 21(2), 333-352. https://doi.org/10.1037/08827974.21.2.333

Desai, S. P., \& Lele, V. (2017). Correlating internet, social networks and workplace-a case of Generation Z students. Journal of Commerce and Management Thought, 8(4), 802-815. https://doi.org/10.5958/0976-478X.2017.00050.7

Dimock, M. (2019). Defining generations: Where millennials end and Generation $Z$ begins. Pew Research Center, 17, 1-7.

Dvořák, M. (2018). Understanding the ephemeral online communication: A uses and gratification perspective. Czech Republic: Masaryk University.

Flecha-Ortíz, J., Santos-Corrada, M., Dones-González, V., López-González, E., \& Vega, A. (2021). Millennials \& Snapchat: Self-expression through its use and its influence on purchase motivation. Journal of Business Research, 125(March), 798-805. https://doi.org/10.1016/j.jbusres.2019.03.005

Gentzler, A. L., Oberhauser, A. M., Westerman, D., \& Nadorff, D. K. (2011). College students' use of electronic communication with parents: Links to loneliness, attachment, and relationship quality. Cyberpsychology, Behavior, and Social Networking, 14(1-2), 71-74. https://doi.org/10.1089/cyber.2009.0409

Handyside, S., \& Ringrose, J. (2017). Snapchat memory and youth digital sexual cultures: Mediated temporality, duration and affect. Journal of Gender Studies, 26(3), 347360. https://doi.org/10.1080/09589236.2017.1280384

Hollan, J., \& Stornetta, S. (1992). Beyond being there. In Proceedings of the SIGCHI Conference on Human factors in Computing Systems (pp. 119-125). ACM Digital Library. https://doi.org/10.1145/142750.142769

Holtzman, S., DeClerck, D., Turcotte, K., Lisi, D., \& Woodworth, M. (2017). Emotional support during times of stress: Can text messaging compete with in-person interactions? Computers in Human Behavior, 71, 130-139. https://doi. org/10.1016/j.chb.2017.01.043

Joinson, A. N. (2008). Looking at, looking up or keeping up with people? Motives and use of Facebook. In Proceedings of the SIGCHI Conference on Human Factors in Computing Systems (pp. 1027-1036). ACM Digital Library. https://doi. org/10.1145/1357054.1357213 
Jurgenson, N. (2011). Digital dualism versus augmented reality. The Society Pages, 24. Retreived from https://hesocietypages.org/cyborgology/2011/02/24/digitaldualism-versus-augmented-reality/

Katz, E., Blumler, J. G., \& Gurevitch, M. (1973). Uses and gratifications research. The Public Opinion Quarterly, 37(4), 509-523. https://doi.org/10.1086/268109

Kaun, A., \& Stiernstedt, F. (2014). Facebook time: Technological and institutional affordances for media memories. New Media \& Society, 16(7), 1154-1168. https://doi.org/10.1177/1461444814544001

Kaye, B. K., \& Johnson, T. J. (2002). Online and in the know: Uses and gratifications of the web for political information. Journal of Broadcasting \& Electronic Media, 46(1), 54-71. https://doi.org/10.1207/s15506878jobem4601_4

Kofoed, J., \& Larsen, M. C. (2016). A snap of intimacy: Photo-sharing practices among young people on social media. First Monday, 21(11). https://doi.org/10.5210/ fm.v21i11.6905

Lenhart, A., Ling, R., Campbell, S., \& Purcell, K. (2010). Teens and mobile phones: Text messaging explodes as teens embrace it as the centerpiece of their communication strategies with friends. Pew Internet \& American Life Project.

Leung, L. (2013). Generational differences in content generation in social media: The roles of the gratifications sought and of narcissism. Computers in Human Behavior, 29(3), 997-1006. https://doi.org/10.1016/j.chb.2012.12.028

Madden, M., Lenhart, A., Duggan, M., Cortesi, S., \& Gasser, U. (2013). Teens and technology 2013. Pew Internet \& American Life Project.

Marwick, A., Fontaine, C., \& Boyd, D. (2017). "Nobody sees it, nobody gets mad": Social media, privacy, and personal responsibility among low-SES youth. Social Media+ Society, 3(2). https://doi.org/10.1177/2056305117710455

Mayer-Schönberger, V. (2011). Delete: The virtue of forgetting in the digital age. New Jersey: Princeton University Press. https://doi.org/10.1515/9781400838455

Mei, S., Chai, J., Wang, S.-B., Ng, C., Ungvari, G., \& Xiang, Y.-T. (2018). Mobile phone dependence, social support and impulsivity in Chinese university students. International Journal of Environmental Research and Public Health, 15(3), 504. https://doi.org/10.3390/ijerph15030504

Melander, L. A. (2010). College students' perceptions of intimate partner cyber harassment. Cyberpsychology, Behavior, and Social Networking, 13(3), 263-268. https://doi. org/10.1089/cyber.2009.0221

Morris, M. R. (2014). Social networking site use by mothers of young children. In Proceedings of the 17th ACM Conference on Computer Supported Cooperative Work \& Social Computing (pp. 1272-1282). ACM Digital Library. https://doi. org/10.1145/2531602.2531603

Nyland, R., Marvez, R., \& Beck, J. (2007). MySpace: Social networking or social isolation. AEJMC 2007 Midwinter Conference. Retrieved from http://works.bepress.com/ rob-nyland/22/

Olson, K. E., O'Brien, M. A., Rogers, W. A., \& Charness, N. (2011). Diffusion of technology: frequency of use for younger and older adults. Ageing International, 36(1), 123-145. https://doi.org/10.1007/s12126-010-9077-9 
Piwek, L., \& Joinson, A. (2016). "What do they Snapchat about?" Patterns of use in timelimited instant messaging service. Computers in Human Behavior, 54, 358-367. https://doi.org/10.1016/j.chb.2015.08.026

Punyanunt-Carter, N. M., De La Cruz, J. J., \& Wrench, J. S. (2017). Investigating the relationships among college students' satisfaction, addiction, needs, communication apprehension, motives, and uses \& gratifications with Snapchat. Computers in Human Behavior, 75, 870-875. https://doi.org/10.1016/j. chb.2017.06.034

Purcell, K., Rainie, L., \& Brenner, J. (2012). Search engine use 2012; 2012. Washington, DC: The Pew Research Center's Internet \& American Life Project.

Quan-Haase, A., \& Young, A. L. (2014). The uses and gratifications (U\&G) approach as a lens for studying social media practice. The Handbook of Media and Mass Communication Theory, 1, 269-286. https://doi.org/10.1002/9781118591178. ch15

Ramsey, M. A., Gentzler, A. L., Morey, J. N., Oberhauser, A. M., \& Westerman, D. (2013). College students' use of communication technology with parents: Comparisons between two cohorts in 2009 and 2011. Cyberpsychology, Behavior, and Social Networking, 16(10), 747-752. https://doi.org/10.1089/cyber.2012.0534

Ramsey, M. A., Oberhauser, A. M., \& Gentzler, A. L. (2015). 10. College students' use of communication technology with parents: Influences of distance, gender, and social presence. In The psychology of social networking, vol. 2 (pp. 128-140). Berlin, Boston: De Gruyter. https://doi.org/10.1515/9783110473858-012

Relander, B. (2014). How to market to Gen Z, the kids who already have $\$ 44$ billion to spend. Entrepreneur Asia Pacific. Retrieved 10 September 2016 from https:// www.entrepreneur.com/article/238998

Roesner, F., Gill, B. T., \& Kohno, T. (2014). Sex, lies, or kittens? Investigating the use of Snapchat's self-destructing messages. In N. Christin, \& R. Safavi-Naini (Eds.), Financial cryptography and data security. FC 2014. Lecture notes in Computer Science, vol. 8437. Springer, Berlin, Heidelberg. https://doi.org/10.1007/978-3662-45472-5_5

Schoenebeck, S. Y. (2013). The secret life of online moms: Anonymity and disinhibition on YouBeMom.com. Proceedings of the International AAAI Conference on Web and Social Media, 7(1), Cambridge, Massachusetts, USA. Retrieved from https:// ojs.aaai.org/index.php/ICWSM/article/view/14379

Seemiller, C., \& Grace, M. (2016). Generation Z goes to college. San Francisco: JosseyBass.

Soffer, O. (2016). The oral paradigm and Snapchat. Social Media + Society, 2(3). https:// doi.org/10.1177/2056305116666306

Statista. (2018). Snapchat Statista Dossier. Retrieved 27 February 2020 from https://www. statista.com/study/12393/social-networks-statista-dossier/19

Sundar, S. S., \& Limperos, A. M. (2013). Uses and grats 2.0: New gratifications for new media. Journal of Broadcasting \& Electronic Media, 57(4), 504-525. https://doi. org/10.1080/08838151.2013.845827

Tapscott, D. (2009). Growing up digital: How the net generation is changing your world. New Delhi: McGraw-Hill. 
Törőcsik, M., Szücs, K., \& Kehl, D. (2014). How generations think: Research on Generation Z. Acta Universitatis Sapientiae, Communicatio, 1(2014), 23-45.

Utz, S., Muscanell, N., \& Khalid, C. (2015). Snapchat elicits more jealousy than Facebook: A comparison of Snapchat and Facebook use. Cyberpsychology, Behavior, and Social Networking, 18(3), 141-146. https://doi.org/10.1089/cyber.2014.0479

Van derKaay, C. D., \& Young, W. H. (2012). Age-related differences in technology usage among community college faculty. Community College Journal of Research and Practice, 36(8), 570-579. https://doi.org/10.1080/10668920903054865

Van Volkom, M., Stapley, J. C., \& Amaturo, V. (2014). Revisiting the digital divide: Generational differences in technology use in everyday life. North American Journal of Psychology, 16(3), 557-574.

Vaterlaus, J. M., Barnett, K., Roche, C., \& Young, J. A. (2016). "Snapchat is more personal": An exploratory study on Snapchat behaviors and young adult interpersonal relationships. Computers in Human Behavior, 62, 594-601. https:// doi.org/10.1016/j.chb.2016.04.029

Vaterlaus, J. M., Jones, R. M., Patten, E. V, \& Cook, J. L. (2015). An exploratory study of time spent with interactive technology and body mass among young adults. Computers in Human Behavior, 52, 107-114. https://doi.org/10.1016/j. chb.2015.05.035

Velez, E. (2014). Intimate publics and ephemerality. Snapchat: A case study. Retrieved 27 February 2020 from http://www.secondshiftblog.com/2014/09/intimatepublicsand-ephemerality-snapchat-a-case-study/

Weaver Lariscy, R., Tinkham, S. F., \& Sweetser, K. D. (2011). Kids these days: Examining differences in political uses and gratifications, Internet political participation, political information efficacy, and cynicism on the basis of age. American Behavioral Scientist, 55(6), 749-764. https://doi.org/10.1177/0002764211398091

Whiting, A., \& Williams, D. (2013). Why people use social media: A uses and gratifications approach. Qualitative Market Research: An International Journal, 16(4), 362369. https://doi.org/10.1108/QMR-06-2013-0041

Williams, A. (2015). Move over, millennials, here comes Generation Z. The New York Times, 18.

Yang, C., Brown, B. B., \& Braun, M. T. (2014). From Facebook to cell calls: Layers of electronic intimacy in college students' interpersonal relationships. New Media \& Society, 16(1), 5-23. https://doi.org/10.1177/1461444812472486 